Bender, A. E. (1954). F. Sci. Fd Agric. 5, 305.

Bender, A. E. (1956). Brit. F. Nutr. ro, 135.

Bender, A. E. (1961). In Progress in Meeting Protein Needs of Infants and Preschool Children. Publ, nat. Res. Coun., Wash., no. 843, p. 407.

Bender, A. E. \& Doell, B. H. (1957). Brit. F. Nutr. I 1, I 40.

Berg, C. P. (1959). In Protein and Amino Acid Nutrition, p. 57. [A. A. Albanese, editor.] New York: Academic Press Inc.

Block, R. J. \& Mitchell, H. H. (1946-7). Nutr. Abstr. Rev. 16, 249.

Block, R. J. \& Weiss, K. (1956). Amino Acid Handbook. Springfield, Ill.; C. C. Thomas.

McDermott, E. E. \& Pace, J. (1960). F. Sci. Fd Agric. Ir, I०9.

Miller, D. S. \& Bender, A. E. (1955). Brit. F. Nutr. 9, 382.

Mitchell, H. H. (1959). In Protein and Amino Acid Nutrition, p. I r. [A. A. Albanese, editor.] New York: Academic Press Inc.

Rutgers University: Bureau of Biological Research (1950). Cooperative Determinations of the Amino Acid Content, and of the Nutritive Value of Six Selected Protein Food Sources. New Brunswick, NJ: Rutgers University Press.

\title{
The concept of agent and target in amino acid interactions
}

\section{By D. Lewis, University of Nottingham School of Agriculture}

It is now generally recognized that the addition to a diet of an amino acid or amino acid mixture beyond the amount required by the animal consuming the diet can on some occasions lead to ill-effects in terms of growth, disproportionate to the amount added. It is possible to attribute all such adverse effects to a single phenomenon, amino acid imbalance (Salmon, 1958), or to attempt to separate them into three categories (Harper, 1958): imbalances, in which the effect of the added amino acid is reversed by supplementing the diet with the first limiting amino acid; antagonisms, in which the effect is reversed by a structurally related amino acid; and toxic effects, in which no simple amino acid supplementation reverses the growth depression. It is not implied that these three categories represent disparate mechanisms, and their continued use seems only to be justified by the apparent absence of any direct evidence to identify a common basis for all the ill-effects that have been recorded (see Harper, 1964). The continuous lack of any substantial evidence to support three distinct mechanisms of interaction makes it necessary still to assume that the situation represents but a single phenomenon.

It can be expected that further information on the nature of the interaction will come from a specific study of the circumstances under which amino acids will bring about and ameliorate a growth-depressing effect. When ill-defined mixtures of amino acids (e.g. proteins or their hydrolysates) are added to a basal diet supporting satisfactory growth it is only possible to acquire further and unnecessary confirmation of the existence of the phenomenon. There is in fact little reason to believe that when mixtures are added the effect is a consequence of more than one of the amino acids present. Each amino acid enters into different pathways of metabolism, and the manner of its involvement in interaction must be understood in terms of its participation in metabolism.

An alternative hypothesis to the division supported by Harper (1958) is to think of the phenomenon as the result of interaction between pairs of amino acids. The 
amino acid which must be added to counteract the growth depression consequent upon the intake of an unbalanced diet may be defined as the target of some unknown mechanism which results in the requirement for that amino acid being increased. The agent of the interaction can be defined as the amino acid whose addition leads to the phenomenon. From such a hypothesis it is possible to build up a picture of the scope, specificity and reversibility of the interaction. The identity can be established of any other target amino acids susceptible to the action of the agent, and conversely alternative agents against the target amino acid can be recognized.

Table I. Basal diet used in trials $A \mathrm{I}$ I, A12 and $A_{14}$ (Smith $\mathscr{E}$ Lewis, 1966)

(Composition expressed as \% of dry matter except for protein which is expressed on an air-dry basis. The supplement contains the levels of amino acid stated. The figures for composition include the supplementary amounts)

\begin{tabular}{lr}
\multicolumn{2}{c}{ Ingredients $(\%)$} \\
Maize meal & 55 \\
Maize gluten meal & 37 \\
Dried whey & 3 \\
Supplement & 5 \\
& \\
DL-Methionine & $0 \cdot$ I \\
DL-Tryptophan & $0 \cdot 2$ \\
L-Tyrosine & $0 \cdot 2$ \\
L-Lysine & 0.6 \\
Glycine & 0.3
\end{tabular}

\begin{tabular}{lr}
\multicolumn{2}{c}{ Composition (\%) } \\
Protein (N $\times 6.25)$ & 21.6 \\
Arginine & 0.79 \\
Histidine & 0.46 \\
Lysine & 1.02 \\
Methionine + cystine & 0.95 \\
Tryptophan & 0.30
\end{tabular}

Table 2. Live-weight gain in trials $A_{11}, A_{12}$ and $A_{14}\left(\right.$ Smith $\mathscr{O}^{\circ}$ Lewis, 1966)

(Mean values ( $g /$ day) for six replicates of ten birds; groups of fifteen birds placed in cages at day-old, reduced to ten at 7 days and experimental diets given)

\begin{tabular}{|c|c|c|c|}
\hline \multicolumn{4}{|c|}{ Treatment } \\
\hline & only & $13 \cdot 2$ & $18 \cdot 7$ \\
\hline & $+0.2 \%$ arginine & $13 \cdot 3$ & I $8 \cdot 5$ \\
\hline & $+0.6 \%$ lysine & I I $\cdot 9$ & $16 \cdot 0$ \\
\hline & + arginine and lysine & $13 \cdot 5$ & $19 \cdot 0$ \\
\hline & SE & \pm 0.25 & \pm 0.3 \\
\hline \multicolumn{4}{|l|}{$\mathrm{A}_{12}$} \\
\hline & only & $12 \cdot 8$ & $18 \cdot 5$ \\
\hline & $+0.2 \%$ arginine & $14 \cdot 2$ & $19 \cdot 3$ \\
\hline & $+0.3 \%$ lysine & 10.9 & $16 \cdot 3$ \\
\hline & +o. I5\% histidine & I $2 \cdot 6$ & 18.0 \\
\hline & + arginine and lysine & $13 \cdot 6$ & 19.1 \\
\hline & + arginine and histidine & $I_{4}^{4} \cdot I$ & 20.6 \\
\hline & SE & \pm 0.3 & \pm 0.5 \\
\hline \multicolumn{4}{|l|}{$\mathrm{A}_{14}$} \\
\hline & only & 12.6 & 13.8 \\
\hline & $+0.2 \%$ arginine & $12 \cdot 5$ & $15 \cdot 0$ \\
\hline & $+0.6 \%$ lysine & 10.0 & $9 \cdot 1$ \\
\hline & $+0.2 \%$ tryptophan & 13.0 & I 4.5 \\
\hline & + arginine and lysine & II.9 & 12.8 \\
\hline & + tryptophan and lysine & $9 \cdot 8$ & $7 \cdot 2$ \\
\hline & + arginine and tryptophan & $12 \cdot 6$ & $13 \cdot 0$ \\
\hline & SE & \pm 0.3 & \pm 0.4 \\
\hline
\end{tabular}


In the light of this hypothesis the interaction between lysine and arginine has been examined on chicks (Smith \& Lewis, 1964, 1966). In a preliminary series of experiments a basal diet was employed marginally adequate in terms of arginine supply (Lewis, Smith \& Payne, I963) but fully adequate in all other amino acids (see Table 1). The addition of lysine to the basal diet (Table 2) resulted in a marked growth depression which was prevented if arginine was also added (treatment AI I). Subsequent experiments were concerned with testing alternatives to lysine as agent of interaction and to arginine as the target. Though some growth depression was recorded on adding histidine (treatment $A_{12}$ ), it was not statistically significant and it cannot be regarded as a potent alternative agent of interaction. In another experiment (treatment $\mathrm{A}_{14}$ ) an effort was made to establish whether tryptophan

'Table 3. Basal diet used in trials $A_{\mathrm{I}} 5$ and $A_{\mathrm{I}} 6$ (Smith $\Xi^{\circ}$ Lewis, 1966)

(Composition expressed as \% of dry matter except for protein which is expressed on an air-dry basis. The supplement contains the levels of amino acid stated. The figures for composition include the supplementary amounts)

\begin{tabular}{lr}
\multicolumn{2}{c}{ Ingredients (\%) } \\
Maize meal & 64 \\
Maize gluten meal & 20 \\
Zein & 7 \\
Dried whey & 3 \\
Supplement & 6
\end{tabular}

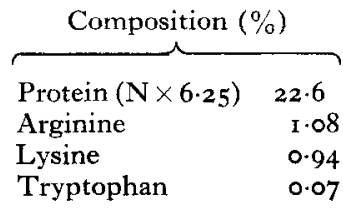

$\begin{array}{ll}\text { DL-Methionine } & 0.1 \\ \text { L-Tyrosine } & 0.1 \\ \text { L-Lysine } & 0.6 \\ \text { L-Arginine } & 0.3 \\ \text { Glycine } & 0.6\end{array}$

Table 4. Live-weight gain in trials $A_{\mathrm{I}} 5$ and $A_{\mathrm{I}} 6$ (Smith $\mathscr{E}^{\circ}$ Lewis, 1966)

(Mean values ( $\mathrm{g} / \mathrm{day}$ ) for six replicates of six birds: groups of ten birds were placed in cages at day-old and reduced to six at 7 days: experimental diets offered from 7 days of age)

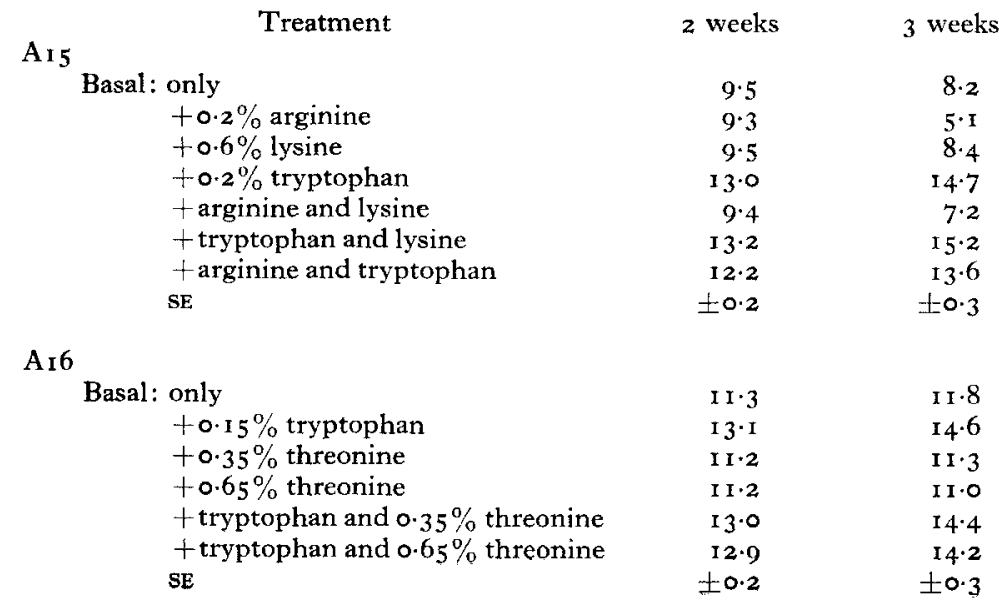


could act as an alternative target amino acid. The growth depression upon adding lysine to the basal diet without the extra tryptophan listed in Table I was not at all prevented by also adding tryptophan.

It is possible that the absence of any response in testing for tryptophan as an alternative target is accounted for by the relatively high tryptophan content of the basal diet in relation to arginine. A further basal diet was therefore prepared (Table 3) in which the tryptophan content was only $0.07 \%$. The addition of tryptophan resulted in a marked growth stimulation (Table 4), but supplementation with lysine did not depress growth. There was, however, a rather unexpected depression on adding arginine alone or in the presence of tryptophan. It is conceivable that these interactions are only found when there is a very delicate balance between pairs or small groups of amino acids and that in this experiment the deficiency in terms of tryptophan was already too gross. Without using purified diets it is not easy to achieve a desired pattern of amino acid balance: efforts are, however, being made to consider other alternative targets to arginine, e.g. histidine (see Winje, Harper, Benton, Boldt \& Elvehjem, 1954) or threonine (see Rosenberg, Culik \& Eckert, 1959).

The basal diet listed in Table 3 (tryptophan-deficient) was also used in a preliminary experiment (AI6) to identify a tryptophan-threonine interaction (see Florentino \& Pearson, 1962). The results in Table 4 show again that tryptophan addition resulted in a growth stimulation: the depression noted on adding threonine was not statistically significant. It is again possible that the tryptophan content was too low for the interaction effect to be clearly demonstrated.

A further series of experiments has been carried out to look in some detail at any distinction that can be made between antagonisms and imbalances. A basal diet was prepared deficient in methionine and only barely adequate in terms of arginine supply. There was a significant growth response on supplementing it with methionine (Table 5), which was not increased when an arginine supplement was also

\section{Table 5. Experiment $D_{2}$ (Lewis $\mathcal{E}^{\circ} D^{\prime}$ Mello, unpublished)}

(Composition of basal diet employed and live-weight gain recorded for six replicates of six birds when the supplements indicated were added to the basal diet)

\begin{tabular}{lc}
\multicolumn{2}{c}{ Composition (\%) } \\
Protein $(\mathrm{N} \times 6.25)$ & 20.0 \\
Arginine & 0.90 \\
Methionine & $0.3 \mathrm{I}$ \\
Methionine and cystine & 0.62 \\
Lysine & $\mathrm{I} \cdot \mathrm{IO}$
\end{tabular}

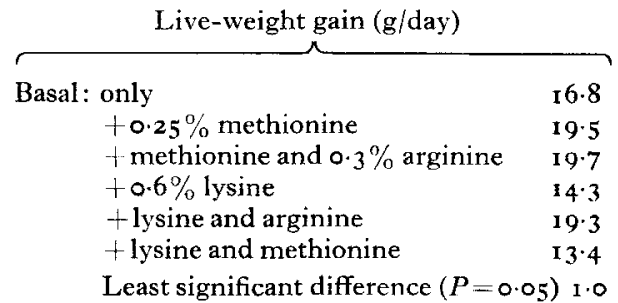

included. The addition of lysine gave a marked growth depression: it was corrected by arginine but not by methionine. It is not necessary to invoke two independently operating growth limitations: the presence of lysine can be said to increase the requirement for arginine to such an extent that it becomes the first limiting amino acid. 
In considering explanations for imbalances and antagonisms Harper (I 964) proposes the same mechanisms - effects upon palatability and food intake, upon absorption and nitrogen retention and upon excretion. The apparent absence of disparate mechanisms associated with the three categories (toxicities, antagonisms and imbalances) renders the classification not particularly useful. It would seem more advantageous to contemplate a common basis: there is in all three a depressed food intake, the patterns of plasma amino acid levels seem to be consistent, and the effect upon blood urea does not appear to vary. The sequence of events envisaged by Harper (1964) to account for the consequences of lack of dietary amino acid balance include a phase of influx of surplus of certain amino acids into the blood stream. This may well be the stage at which to seek the explanation of the phenomenon, but it must be in the light of the manner of involvement of particular amino acids in metabolic pathways.

The hypothesis can be put forward that the extent to which an amino acid causes a deleterious effect when present in excess is related to the ease with which it enters into pathways of katabolism and is removed from the metabolic pool. The manner of its effect might be related to the other amino acids associated with similar katabolic routes. One may, for example, contrast the behaviour of lysine and arginine: the former is, in the mammal at least, relatively metabolically inert and is a potent agent of interaction, whereas the reverse is true with arginine. A study of pathways of katabolism of amino acids in the bird has therefore been initiated.

Generally L-amino acid oxidases are of limited occurrence and low activity in mammalian systems. The oxidation of L-amino acids by chicken liver microsomes has, however, been demonstrated by Struck $\&$ Sizer (I960). The oxidative properties of avian liver preparations in the presence of added amino acids were examined by Lewis \& Smith (1963). The addition of L-lysine to an acetone powder of various turkey liver preparations led to a substantial increase in oxygen uptake (Table 6). The activity of chick liver preparations in this respect was considerably lower, perhaps accommodating the embarrassing effects of surplus dietary lysine. However,

Table 6. Oxygen uptake of acetone powders of chick and turkey liver preparations (Lewis, Smith $\mathscr{E}^{\circ}$ Shinwari, unpublished)

(Incubation at $37^{\circ}$ in presence of $2 \times 10^{-4} \mathrm{M}-C N^{-}$; molarity of substrate, $0.02 \mathrm{M} ; \mathrm{pH} 8.0$; activity expressed as $\mu$ moles $\mathrm{O}_{2}$ absorbed/g powder per $\mathrm{h}$ )

$\begin{array}{lcccc}\begin{array}{c}\text { Whole } \\ \text { liver }\end{array} & \begin{array}{c}\text { Mitochondrial } \\ \text { particles } \\ \text { Turkey }\end{array} & \begin{array}{c}\text { Fraction } \\ \text { precipitated } \\ \text { at pH } 5.5\end{array} & \text { Remainder } \\ \text { Control } & 19.9 & 12.5 & 15.4 & 17.7 \\ + \text { Lysine } & 27.5 & 15.6 & 23.7 & 26.2 \\ \text { Control } & & \text { Chick } & & 7 \cdot 1 \\ \text { +Lysine } & 11.5 & 9.2 & 18.5 & 7.6\end{array}$


a detectable increase in oxygen uptake was recorded with one fraction-that precipitated at $\mathrm{pH} 5.5$ from the supernatant liquid after centrifuging the initial liver homogenate at $10000 \mathrm{~g}$. Cyanide was added in an attempt to inhibit cytochrome oxidase and other oxidase activities. The release of ammonia and appearance of a keto group could be demonstrated. A further examination of this $\mathrm{pH} 5.5$ fraction was carried out with other amino acids (Table 7 ). Both arginine and histidine were readily oxidized. The results on incubation with hydroxylamine confirmed that the process was not essentially one involving transdeamination and L-glutamic dehydrogenase.

\section{Table 7. Oxygen uptake of the 'pH $5 \cdot 5$ ' fraction of chick liver} (Lewis, Smith Eீ Shinwari, unpublished)

(Incubation at $37^{\circ}$ in presence of $2 \times 10^{-3} \mathrm{M}-\mathrm{NH}_{2} \mathrm{OH}$; substrate, $0.03 \mathrm{M} ; \mathrm{pH} \mathrm{8.0;} \mathrm{activity} \mathrm{expressed} \mathrm{as}$ $\mu$ moles $\mathrm{O}_{2}$ absorbed/g powder per $\mathrm{h}$ )

Control
Histidine
Arginine
Leucine
Lysine
Tryptophan
Glutamic acid
Phenylalanine
Methionine
Valine

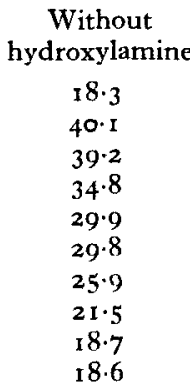

With
hydroxylamine
$17 \cdot 4$
$38 \cdot 4$
-
$29 \cdot 7$
-
$13 \cdot 1$
-
-

Table 8. Oxidase activity of liver preparations obtained from chicks given diets of different lysine contents (Lewis, Smith $\wp^{\circ}$ Shinwari, unpublished)

(Mean oxygen uptake of acetone-dried ' $\mathrm{pH} 5.5$ ' fraction of liver in presence of 0.02 M-substrate and $2 \times 10^{-4} \mathrm{M}^{-\mathrm{CN}^{-}}$at $37^{\circ}$ and $\mathrm{pH} 8.0$; substrate $0.02 \mathrm{M}$; activity expressed as $\mu \mathrm{moles} \mathrm{O}_{2}$ absorbed/g powder per $h$; each group is of ten birds of 6 weeks of age)

\begin{tabular}{|c|c|c|c|c|}
\hline \multicolumn{5}{|c|}{ Normal diet $(0.9 \%$ lysine $)$} \\
\hline Control & I4. $\mathrm{I}$ & $12 \cdot I$ & $13 \cdot 5$ & $13 \cdot 2$ \\
\hline + Leucine & $16 \cdot 5$ & 18.8 & $17 \cdot 3$ & 17.5 \\
\hline + Lysine & $16 \cdot 3$ & I $4 \cdot 1$ & $14 \cdot 1$ & 14.8 \\
\hline \multicolumn{5}{|c|}{ Excess lysine (1.5\% lysine) } \\
\hline Control & I $1 \cdot 6$ & $13 \cdot 0$ & 14.4 & \\
\hline + Leucine & 14.5 & $18 \cdot 3$ & 19.9 & 17 \\
\hline + Lysine & 16.8 & $16 \cdot 9$ & $17 \cdot 2$ & $17 \cdot 0$ \\
\hline
\end{tabular}

From these observations it can at least be suggested that a mechanism which might account for some of the phenomenons associated with lack of adequate dietary amino acid balance, is an increase in oxidative katabolism in response to excess amino acids which emphasizes the inadequacy of the limiting amino acid. The possibility of an adaptive increase in activity of the L-amino acid oxidase in response to dietary intake has been demonstrated (Table 8). Insufficient results are available on the basis of which to decide whether these small differences are significant. 
It is possible that the continued study of these phenomenons in the light of the hypothesis of an agent-target interaction and a limitation of disposal by katabolic pathways may throw some light on the mechanisms whereby the recorded growth depressions are brought about. Further work is needed to define the specificity of the established interactions-the identity of alternative agents and targets-and to associate awareness of the involvement of individual amino acids in metabolic pathways.with patterns of plasma amino acid levels and nitrogenous excretory compounds.

\section{REFERENCES}

Florentino, R. F. \& Pearson, W. N. (1962). F. Nutr. 78, 101.

Harper, A. E. (1958). Ann. N.Y. Acad. Sci. 69, 1025.

Harper, A. E. (1964). In Mammalian Protein Metabolism. Vol. 2, p. 87. [H. N. Munro and J. B. Allison, editors]. New York: Academic Press Inc.

Lewis, D. \& Smith, G. H. (1963). Proc. int. Congr. Nutr. vi. Edinburgh, p. 479.

Lewis, D., Smith, G. H. \& Payne, C. G. (1963). Brit. F. Nutr. 17, 415.

Rosenberg, H. R., Culik, R. \& Eckert, R. E. (1959). F. Nutr. 69, 212.

Salmon, W. D. (1958). Amer. F. clin. Nutr. 6, 487.

Smith, G. H. \& Lewis, D. (1964). Proc. Nutr. Soc. 23, xxviii.

Smith, G. H. \& Lewis, D. (I g66). Brit. F. Nutr. (In the Press.)

Struck, J. \& Sizer, I. W. (1960). Arch. Biochem. Biophys. 9o, 22.

Winje, M. E., Harper, A. E., Benton, D. A., Boldt, R. E. \& Elvehjem, C. A. (1954). F. Nutr. 54, r 55

\section{A comparative study of performance on high-protein diets of unbalanced amino acid composition}

\section{By K. J. Carpenter and H. J. H. de Muelenaere*, School of Agriculture, University of Cambridge}

It is convenient to compare food proteins by a standardized procedure using one fixed level of protein in each test diet. The level is chosen to be sufficiently low so that the response, even for a good protein, is suboptimal. Such experiments can answer some questions, but not "how much of one particular protein food must be used in order to obtain the desired rate of growth (or performance) in a particular context?'.

Where the protein of food $A$ has given a lower value than the protein of food $B$, we may still reasonably consider using $A$ rather than $B$ provided that the total cost of the most economic and still satisfactory diet based on $A$ is less than that of any similarly satisfactory diet based on $B$. Since the combination of foods available is so great and their relative prices so variable, one has usually to attempt to predict the quality of a particular diet from its chemical composition.

\section{Groundnut flour as an example}

The difficulties are best seen with an actual example. Groundnut flour is about the least well-balanced of the common protein-rich foods in its amino acid composition and yet has been recommended for improving weanling children's diets

\footnotetext{
"On leave from the Department of Biochemistry, University of Natal,
} 